\title{
ARTE, GÊNERO E CULTURA VISUAL - UM OLHAR PARA AS ARTISTAS MULHERES
}

\author{
Fabiana Lopes de Souza ${ }^{1}$ \\ Maristani Polidori Zamperetti ${ }^{2}$
}

Resumo: Este texto busca entrelaçar os temas de Cultura Visual, Artes Visuais e Gênero, com o objetivo de argumentar a favor de uma educação crítica das imagens, ampliando a compreensão das visualidades cotidianas. A presença feminina na cultura e nas artes visuais não tem merecido destaque, pois em toda história da arte ocidental, as mulheres não têm sido vistas como protagonistas dos fazeres artísticos. Assim, o conhecimento das artistas mulheres, em especial, pode favorecer uma nova apreensão das visualidades contemporâneas, buscando superar as desigualdades de gênero. Portanto, verifica-se a necessidade dos estudos sobre as pedagogias culturais, visando ampliar os entendimentos sobre os espaços e as maneiras como a cultura se torna visível e o visível se torna cultura.

Palavras-chave: Cultura visual; Ensino de Artes Visuais; Gênero.

\section{ART, GENDER AND VISUAL CULTURE - A LOOK AT WOMEN'S ARTISTS}

Abstract: This text seeks to interweave the themes of Visual Culture, Visual Arts and Gender, in order to argue for a critical education of images, broadening the understanding of everyday visuals. The feminine presence in culture and the visual arts has not deserved prominence, because in all history of Western art, women have not been seen as protagonists of artistic actions. Thus, the knowledge of women artists, in particular, may favor a new apprehension of contemporary visuals, seeking to overcome gender inequalities. Therefore, there is a need for studies on cultural pedagogies in order to broaden the understanding of the spaces and the ways in which culture becomes visible and the culture becomes visible.

Keywords: Visual culture; Teaching visual arts; Gender.

\footnotetext{
${ }^{1}$ Mestra em Artes Visuais. Especialista em Artes -Ensino e Percursos Poéticos (CA/UFPel). Professora de Artes Visuais na rede municipal (Pelotas, RS). Tutora a distância no Curso e Filosofia (UFPel).

2 Doutora em Educação. Professora do Centro de Artes (UFPel) e do Programa de Pós-Graduação em Educação (UFPel), onde atua como orientadora de Mestrado e Doutorado. Líder do Grupo de Pesquisa: Pesquisa, Ensino e Formação Docente nas Artes Visuais (CNPQ).
} 


\section{Cultura visual e pedagogias culturais}

$\mathrm{Na}$ atualidade, os meios de comunicação de massa e o universo visual invadem o cotidiano, trazendo questões que necessitam serem melhor explicitadas, e portanto, estudadas, buscando uma abordagem crítica e consciente. Essas imagens são consumidas e retroalimentadas, na medida em que podem ser reproduzidas, fazendo parte da nossa subjetividade, como apropriação ou deslocamento. Assim, conforme aponta Baitello Jr.: "Alimentar-se de imagens significa alimentar imagens, conferindo-lhes substância, emprestando-lhes os corpos. Significa entrar dentro delas e transformar-se em personagem [...]. Ao contrário de uma apropriação, trata-se aqui de uma expropriação de si mesmo" (2005, p. 97).

Objetos e artefatos visuais estão diretamente ligados à formação identitária de adultos, adolescentes e crianças cuja influência para a obtenção desses objetos e artefatos é estimulada diariamente através de anúncios, propagandas e outros meios de comunicação passando a fazer parte da vida das pessoas.

Com isso, destaca-se a necessidade dos estudos sobre a cultura visual, emergentes dos Estudos Culturais para uma melhor compreensão do mundo globalizado e das relações que se estabelecem entre os sujeitos, a partir destas interações.

De acordo com Hall, quanto mais a vida social se torna mediada pelo mercado global de estilos:

[...] lugares e imagens, pelas viagens internacionais, pelas imagens da mídia e pelos sistemas de comunicação globalmente interligados, mais as identidades se tornam desvinculadas desalojadas de tempos, lugares, histórias e tradições específicos e parecem "flutuar livremente" (2005, p.75).

O surgimento dos Estudos Culturais (Cultural Studies) se deu através do Centre for Contemporary Cultural Studies (CCCS) em 1964, na Universidade de Birmingham no Reino Unido. Uma definição para o termo, de acordo com os autores Nelson et al (2005), é de que os Estudos Culturais

[...] constituem um campo interdisciplinar, transdisciplinar e algumas vezes contra-disciplinar que atua na tensão entre duas tendências para abranger tanto uma concepção ampla, antropológica, de cultura, quanto uma concepção humanística de cultura [...] eles se desenvolveram a partir de análises das sociedades industriais modernas [...] argumentam que todas as formas de produção cultural precisam ser estudadas em relação a outras práticas culturais e às estruturas sociais e históricas (2005, p.13). 
Os Estudos Culturais atuam na investigação das práticas e produções culturais, e a contribuição destas para a concepção de cultura.

Dentre os principais autores que influenciaram na criação dos conceitos sobre Estudos Culturais estão: Raymond Willians, E.P Thompson e Richard Hoggart. Estes autores têm uma abordagem afirmativa de que, através da análise do comportamento de uma sociedade, é possível perceber uma padronização das pessoas desde o momento do que é compartilhado e consumido por elas, formando então a cultura de uma sociedade. Outro autor importante dos Estudos Culturais foi Stuart Hall, que substituiu Hoggart na direção do CCCS, entre 1969 e 1979. Hall foi responsável pelos estudos etnográficos, dos meios massivos e das subculturas, produzindo muitos artigos (ESCOSTEGUY, 2010).

A partir destas pesquisas, muitos campos de conhecimento ampliaram seu repertório de análises, voltando-se para os seus próprios estudos, na busca de novas perspectivas teóricas. Assim, a pedagogia foi uma das áreas que, a partir do campo de conhecimento dos Estudos Culturais, teve seu campo ampliado e ressignificado.

Indícios apontam ter sido a partir da aproximação entre Estudos Culturais e Educação que as análises inserindo a pedagogia dentro de uma rede de significações relacionada com cultura, política e poder encontraram embasamento teórico. Foi neste cenário que o conceito de pedagogias culturais surgiu como uma produtiva ferramenta teórica acionada para discutir a relação entre artefatos da cultura e processos educativos (COSTA; ANDRADE, 2015, P. 49).

Para Giroux (1995), o entendimento de que ocorre pedagogia e processos educativos em todo o lugar em que o conhecimento é produzido, e que os saberes resultantes destas situações, extrapolam os limites impostos pelas instituições, como a escola, por exemplo, nos leva a compreender a cultura como uma área privilegiada de produção de práticas culturais de significação que podem, porventura, educar. De forma semelhante, Giroux e McLaren, sustentam que:

Existe pedagogia em qualquer lugar em que o conhecimento é produzido, em qualquer lugar em que existe a possibilidade de traduzir a experiência e construir verdades, mesmo que essas verdades pareçam irremediavelmente redundantes, superficiais e próximas ao lugar-comum (1998, p. 144).

A cultura visual, outro campo de estudos derivado dos Estudos Culturais, foi institucionalizado no início dos anos 90 nos Estados Unidos (KNAUSS, 2006) ${ }^{3}$. A cultura

\footnotetext{
${ }^{3}$ Knauss (2006) em seu texto "O desafio de fazer História com imagens: arte e cultura visual" faz referência a dois livros sobre o campo dos estudos visuais ou da cultura visual para situar historicamente o surgimento do termo cultura visual: ELKINS, James. Visual studies: essays on verbal and visual representation. New
} 
visual é um campo de estudos multidisciplinar que abrange não só as artes, mas também outras áreas de conhecimento como: a sociologia, a psicologia, a antropologia, entre outras.

Para Martins, a cultura visual se configura como um campo amplo,

múltiplo, em que se abordam espaços e maneiras como a cultura se torna visível e o visível se torna cultura. Corpus de conhecimento emergente, resultante de um esforço acadêmico proveniente de Estudos Culturais, a cultura visual é considerada um campo novo em razão do foco no visual com prioridade da experiência no cotidiano" (2005, p.135).

Os estudos referentes à cultura visual nas artes vão além das visualidades artísticas, procurando investigar também as imagens produzidas pela mídia e todas as provenientes da vida cotidiana, pois estas atuam na constituição de pedagogias culturais.

As imagens produzem sentidos e processos de identificação, fazendo parte da vida das pessoas e do cotidiano escolar. Dentro e fora da escola estudantes e professores estão expostos as mais variadas formas de visualidades seja pelos programas de $\mathrm{TV}$, internet, vídeo games e/ou propagandas publicitárias. Além disso, imagens de personagens infantis ou juvenis apresentam-se estampadas nos materiais escolares e roupas dos estudantes e estes passam a identificar-se com as mesmas sem um processo reflexivo. Estas visualidades acabam influenciando as crianças e os adolescentes em suas maneiras de ser e estar no mundo contemporâneo. Com isso torna-se necessário uma educação para as visualidades.

Hernández (2000), chama a atenção para a importância da decodificação de símbolos e signos presentes nas imagens da cultura visual e o quanto o estudo das mesmas podem auxiliar os indivíduos a terem uma melhor percepção sobre si mesmos e sobre o mundo em que estão inseridos. Segundo Hernández, a cultura visual contribui

para que os indivíduos fixem as representações sobre si mesmos e sobre o mundo e sobre seus modos de pensar-se. A importância primordial da cultura visual é mediar o processo de como olhamos e como nos olhamos, e contribuir para a produção de mundos [...] (2000, p.52).

As pessoas são influenciadas na construção de suas identidades, e a cultura visual acaba transmitindo valores e interferindo nas subjetividades destas pessoas. Como exemplo disso, encontram-se as imagens e objetos que são vivenciados e consumidos diariamente por crianças, jovens e adolescentes. Ao tratar de uma perspectiva educativa, Hernández, aponta que

York/London: Routledge, 2003 e DIKOVITSKAYA, Margaret. Visual culture: the study of the visual after the cultural turn. Cambridge, Ms./ London: The MIT Press, 2005. 
[...] os objetos da cultura visual que maior presença têm entre os meninos, as meninas e os adolescentes são os que recobrem as paredes dos quartos, as imagens das pastas da escola, as revistas que leem, os programas de televisão a que assistem, as representações dos grupos musicais, os jogos de computador, suas imagens na Internet, a roupa, seus ícones populares, etc. $(2000$, p.136).

Uma educação baseada nas imagens da cultura visual deve levar em conta as experiências visuais dos estudantes, ajudando-os na compreensão destas visualidades sem interferir nas suas preferências e gostos por determinados objetos e/ou artefatos visuais. D

De acordo com Hernández o propósito da compreensão crítica

e performativa da cultura visual é procurar não destruir o prazer que os estudantes manifestam, mas "explorá-lo para encontrar novas e diferentes formas de desfrute", oferecendo aos alunos possibilidades para outras leituras e produções de "textos", de imagens e de artefatos (2007, p.71).

O professor de Artes Visuais será mediador e provocador no processo educativo com o estudo das imagens da cultura visual, ajudando o aluno a adquirir novos conhecimentos, podendo este atribuir novos sentidos e significados as visualidades presentes na vida cotidiana.

As imagens são importantes para promover o olhar crítico e estético dos estudantes, desde as reproduções de obras de Arte do passado até as imagens midiáticas veiculadas constantemente, que nos invadem com seus anúncios do que é bom, de como devemos ser, nos comportar e nos vestir. Em conformidade com Hernández, [...] é necessário recordar

que uma das maneiras mais notórias pelas quais as mídias, as representações e as práticas da cultura visual posicionam crianças e jovens é através dos "textos" da cultura popular, em particular dos que tendem a criar identidades de etnia, gênero, sexo e consumidor (2007, p.74).

As identidades vão modificando através das relações estabelecidas com o universo visual, imagens midiáticas e de consumo como também da inter-relação entre as pessoas.

O acesso às mais variadas imagens se dá pelos meios de tecnologia de informação e comunicação. É possível perceber na contemporaneidade crianças, adolescentes, jovens e adultos conectados o tempo todo à internet com seus celulares, tablets, computadores e notebooks, isso sem falar nos programas de TV, jogos de computadores entre outros.

Para Hernández, "[e]m um mundo dominado por dispositivos visuais e tecnologias da representação (as artes visuais como tais), nossa finalidade educativa 
deveria ser a de facilitar experiências críticas reflexivas" (2007, p.25). Além do estudo das imagens da cultura visual contemporânea nas aulas de Artes Visuais, os estudantes poderão compreender o quanto estas imagens podem influenciá-los sobre seus comportamentos e na construção de suas identidades.

Ainda sobre construção de identidades, Meyer (2013) aborda que os indivíduos aprendem desde cedo a ocupar e reconhecer seus lugares sociais de forma naturalizada, por isso a autora afirma que trabalhar com o conceito de pedagogias culturais resultantes das noções de educação e educativo, abrange forças e processos que incluem a família e a escolarização, sem limitar-se as mesmas. De acordo com Meyer, existem ainda as forças dos meios de comunicação de massa,

os brinquedos e jogos eletrônicos, o cinema, a música, a literatura, os chamados grupos de iguais, os quais produzem, por exemplo, diferentes e conflitantes formas de conceber e de viver o gênero e a sexualidade, de conceber e de se relacionar com autoridades instituídas, de conhecer o eu e o outro, e que redefinem mesmo os modos com que temos teorizado o currículo, o ser professor, o ser aluno e os processos de ensino e aprendizagem (2013, p. 24).

Desta forma, é fundamental o questionamento sobre as imagens e demais artefatos midiáticos, pois estes produzem maneiras de ser e estar na sociedade, ocasionando modificações culturais que chegam à educação e demais instituições sociais, resultando em pedagogias culturais.

\section{Gênero - definindo a temática}

Os indivíduos passam por processos de reconhecimento do eu e do outro, reprodução de comportamentos e modos de ser que incluem gênero e sexualidade, entre outros, instituídos não só pela família e escola, como também pelos meios de comunicação e informação.

A partir de referências pós-estruturalistas, Louro (2014) analisa a produção das diferenças e das desigualdades sexuais e de gênero articulando com outras questões sociais como: classe, raça e etnia.

O gênero é um elemento constitutivo das relações sociais baseadas nas diferenças percebidas, implicando em símbolos culturalmente construídos e conceitos normativos que interpretam estes símbolos. Gênero é uma 
[...] forma de indicar "construções culturais" - a criação inteiramente social de ideias sobre os papéis adequados aos homens e às mulheres. Trata-se de uma forma de se referir às origens exclusivamente sociais das identidades subjetivas de homens e de mulheres. "Gênero" é, segundo esta definição, uma categoria social imposta sobre um corpo sexuado. [Enfatiza] todo um sistema de relações que pode incluir o sexo, mas não é diretamente determinado pelo sexo, nem determina diretamente a sexualidade (SCOTT, 1995, p. 75-6).

Ainda sobre gênero, Butler (2007) causa questionamentos ao tratar das identidades sexuais não como algo natural ou dado, mas como o resultado de práticas repetidas, discursivas e performativas de gênero - uma invenção cultural.

A construção das identidades femininas e masculinas acontecem a partir das relações, representações e práticas sociais, com isso, o conceito de gênero "[...] passa a exigir que se pense de modo plural, acentuando que os projetos e as representações sobre mulheres e homens são diversos" (LOURO, 2014, p. 27).

Em relação à construção escolar das diferenças, Louro discute como a escola produz as diferenças e desigualdades entre os sujeitos, classificando-os de uma maneira hierárquica. "A escola que nos foi legada pela sociedade ocidental moderna começou por separar adultos de crianças, católicos e protestantes. Ela também se fez diferente para os ricos e para os pobres e ela imediatamente separou os meninos das meninas" (LOURO, 2014, p. 61).

A escola institui modelos, maneiras de ser e estar em seu espaço, demarcando diferenças. Tudo o que a escola apresenta aos sujeitos acaba produzindo múltiplos sentidos para os mesmos, pois os sentidos

[...] precisam estar afiados para que sejamos capazes de ver, ouvir, sentir as múltiplas formas de constituição dos sujeitos implicadas na concepção, na organização e no fazer cotidiano escolar. O olhar precisa esquadrinhar as paredes, percorrer os corredores e salas, deter-se nas pessoas, nos seus gestos, suas roupas; é preciso perceber os sons, as falas, as sinetas e os silêncios; é necessário sentir os cheiros especiais; as cadências e os ritmos marcando os movimentos de adultos e crianças (LOURO, 2014, p. 63).

É preciso estar atento e perceber cada detalhe do cotidiano escolar, mesmo assim cada pessoa terá um olhar e uma maneira diferente de estabelecer sentidos ao que foi percebido ou experienciado por ela.

Tempo e espaço foram aprendidos e interiorizados por diferentes grupos sociais ao longo da história e assim suas concepções tornaram-se "naturais"; a escola é um destes 
espaços em que os sentidos são treinados e considerados como "naturais", por isso é sempre importante desconfiar do que é tomado como "natural".

Ao se tratar de sexualidade e espaço escolar, aqueles que não se encaixam dentro da normativa heterossexual quanto ao ser masculino e feminino, não são percebidos ou são tratados como problemas.

A escola, ao mesmo tempo, que transmite conhecimentos, também fabrica sujeitos e produz identidades, sejam elas de gênero, classe ou etnia e estas identidades são produzidas através de relações de desigualdade (LOURO, 2014).

Ainda sobre diferenças, a partir da perspectiva dos estudos culturais, Silva argumenta que identidade e diferença são cultural e socialmente produzidas, por isso precisam ser questionadas. A identidade,

[...] tal como a diferença, é uma relação social. Isso significa que sua definição - discursiva e linguística - está sujeita a vetores de força, a relações de poder. Elas não vivem harmoniosamente, lado a lado, em um campo sem hierarquias; elas são disputadas (SILVA, 2012, p. 81).

As relações de poder demarcam as diferenças, dividindo, classificando, incluindo e excluindo os sujeitos em determinados grupos sociais e culturais. É preciso questionar a maneira pela qual identidade e diferença se constituem, especialmente em relação à "normalidade", palavra bastante discutida quanto ao seu significado.

\section{Gênero e arte - a presença do feminino nas imagens}

A área da cultura e das artes visuais é ainda uma atividade dominada e reconhecida pela presença dos homens. Embora este fato possa estar em constante debate, é notável a maior incidência da divulgação de imagens e obras artísticas criadas por homens. As mulheres, provavelmente devido à sua aparição como modelos de desenhos, pinturas, gravuras e outras artes, são mais reconhecidas por serem retratadas e menos, como protagonistas e autoras destas.

A partir dos anos 60, com o movimento feminista, é que surgem autoras discutindo o papel da mulher na sociedade, e é este fato que ocasiona também mudanças na vida das mulheres artistas, que começam a produzir obras que buscam ressaltar questões próprias ao sexo feminino. Na época, a arte dessas mulheres passa a ser reconhecida como arte feminista, visto que produz visibilidade e busca reivindicar direitos para as mulheres.

Assim, segundo Grosenick, [...] as mulheres começam a exigir seus lugares nos museus e na história da arte, 
[...] a se organizar e a montar suas próprias exposições, a dirigir suas próprias galerias e a dar aulas particulares. Foi a forma encontrada para burlar as estruturas ainda dominadas pelos homens e colocar como tema central o feminino, a perspectiva deste $(2003$, p. 15).

A seguir apresentamos, de forma sucinta, algumas artistas que trabalham com temáticas de gênero e/ou sexualidade e feminismo, dentre elas: o grupo estadunidense Guerrilla Girls e as artistas brasileiras Lygia Clark e Rosana Paulino.

Guerrilla Girls (Fig. 1) é um grupo de artistas anônimas que usam máscaras de gorila em suas aparições públicas para denunciar e causar questionamentos.

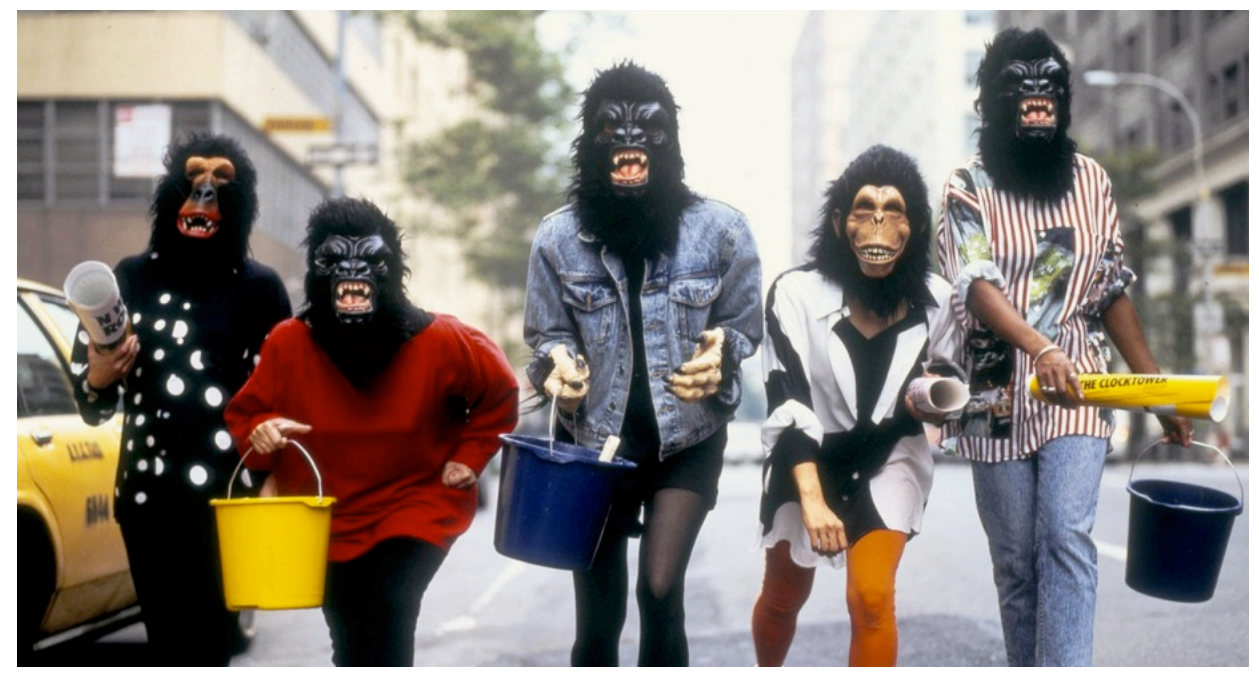

Figura 1: Guerrilla Girls em Nova Iorque, 1985. Fonte: Foto de George Lange. REVISTA CULT, 2017.

O grupo foi formado em Nova York em 1985 com a intenção de trazer as questões de diferenças de gênero e desigualdade racial nas Artes Visuais.

As Guerrilla Girls utilizam pseudônimos como tributo às grandes mulheres fotógrafas, escritoras, pintoras e artistas de diferentes nacionalidades e épocas - como Georgia O'Keeffe, Käthe Kollwitz e Anaïs Nin, dentre outras conhecidas. Estas referências artísticas carregam a condição de sua ausência, pois todas, mortas, evidenciam a passagem às vezes, breve ou mesmo, a pouca visibilidade destas no campo artístico (GUERRILLA GIRLS, 2017).

Quando questionadas sobre a razão de usarem o nome "Guerrilheiras", Georgia O’Keeffe falando em nome do grupo, afirma que: "Queríamos brincar com o medo da guerra de guerrilha, fazer com que as pessoas temessem quem seríamos e aonde atacaríamos a seguir. Além disso, "guerrilha" parece tão bom com "menina"4.

\footnotetext{
${ }^{4}$ Tradução do inglês realizado pelas autoras, a partir de entrevista disponível no site do coletivo.
} 
O cartaz feito pelo grupo (Fig. 2), em que está escrito: “As mulheres precisam estar nuas para entrar no Metropolitan Museum? Menos de 5\% dos artistas nas seções de Arte Moderna são mulheres, mas $85 \%$ dos nus são femininos" ressalta a problemática da inserção feminina no campo da arte.

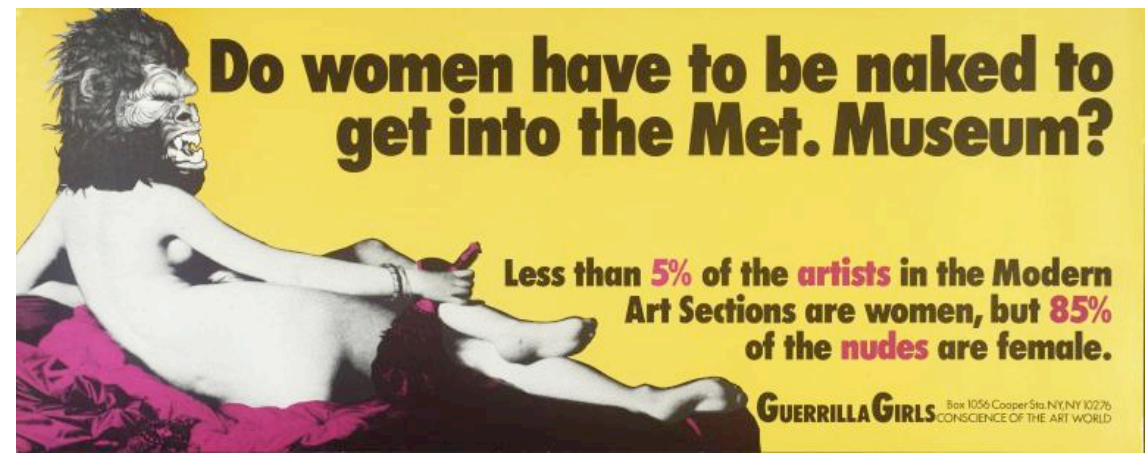

Figura 2: Guerrilla Girls - “Do Women Have to be Naked to Get into the Met. Museum?”(1989). Fonte: TATE, 2017.

A mensagem do cartaz expressa a invisibilidade da mulher na história da arte como criadora, e ainda a tradição dos nus femininos na pintura clássica. O cartaz faz referência à pintura (óleo sobre tela): "A Grande Odalisca", pintada em 1814 (Fig. 3) por Jean Auguste Dominique Ingres ${ }^{5}$.

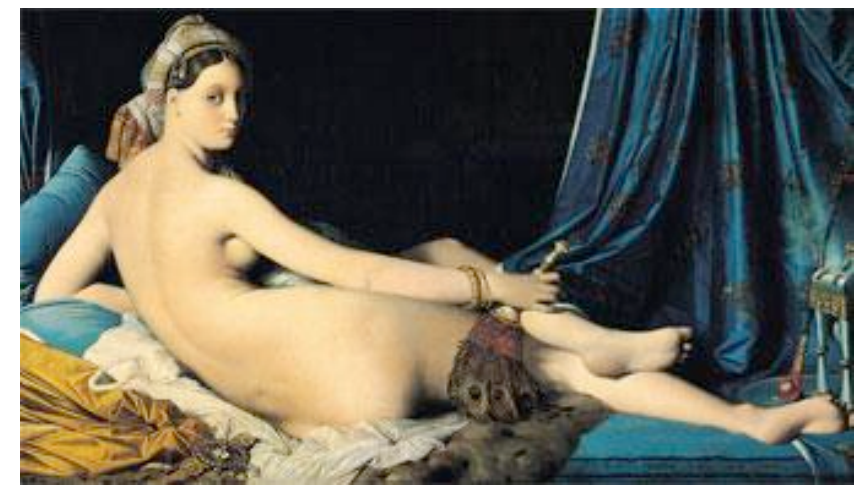

Figura 3: A Grande Odalisca (1814).

Fonte: UNIVERSIA, 2017.

A obra evidencia a condição de objeto das mulheres na História da arte ocidental, demonstrando uma cultura patriarcal e machista, na qual o nu feminino era um tema de representação recorrente.

\footnotetext{
5 Ingres (1780-1867) foi um celebrado pintor e desenhista francês, atuando na passagem do neoclassicismo para o romantismo (ENCYCLOPEDIA BRITANNICA, 2017).
} 
Linda Nochlin, historiadora de arte, em artigo publicado em 1971 questiona sobre a ausência de mulheres artistas. A partir de seu campo de estudo entende que a arte enquanto disciplina demarca o espaço para os sujeitos que fazem parte da história da arte.

A culpa não está nos astros, em nossos hormônios, nos nossos ciclos menstruais ou em nosso vazio interior, mas sim em nossas instituições e em nossa educação, entendida como tudo o que acontece no momento que entramos nesse mundo cheio de significados, símbolos, signos e sinais" (NOCHLIN, 2016, p. 8).

Lygia Clark $^{6}$ criou a série Roupa-corpo-roupa em 1967. Essa obra se tratava de dois macacões vestidos por um homem e uma mulher para que esses pudessem ter a percepção de estar dentro de um corpo de outro sexo (Fig. 4). Na obra, os dois macacões não têm distinções externas de feminino ou masculino, o que diferencia os sexos são sentidos apenas no interior da peça. Para concretização da obra, era necessário que houvesse a presença de um homem e uma mulher, para que cada um pudesse vestir um macacão com os enchimentos que davam a sensação do corpo oposto, homem-mulher, mulher-homem. Essa necessidade vinha da proposta de Lygia Clark de alterar a percepção do sexo, uma pretensa inversão de gênero.

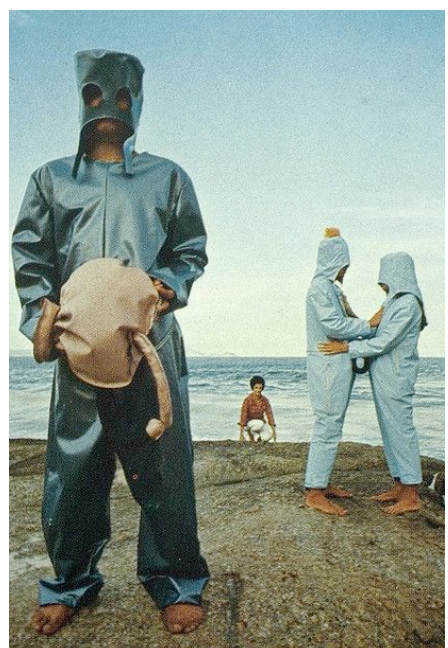

Figura 4: O Eu e o Tu (1967), da série: Roupa-Corpo-Roupa. Fonte: PERFORMING USER, 2017.

O corpo do macacão impossibilita a visão e a audição cobrindo os olhos e as orelhas, e um tubo de borracha na altura do umbigo interliga ambos. A intenção da artista é que haja o toque e que o casal busque descobrir por meio da sensação das mãos o corpo do

\footnotetext{
${ }^{6}$ Lygia Pimentel Lins (1920-1988) foi uma pintora e escultora brasileira contemporânea que se autointitulava "não artista" (ITAÚ CULTURAL, 2017).
} 
outro. Em cada roupa há enchimentos que causam sensação de distinção sexual, porem invertidos, como, por exemplo, a presença de pelos no peito feminino.

Essa obra gera o questionamento do corpo, do que é um corpo feminino e/ou masculino, as sensações causadas pela mesma podem sugerir o gênero como independente do sexo, o próprio gênero como um conceito que oscila (BORTOLON, 2015).

Recentemente a obra de Lygia Clark - O Eu e o Tu - esteve presente na exposição Queermuseu - Cartografias da Diferença na Arte Brasileira (Fig. 5), apresentada no Santander Cultural, inaugurada em 15 de agosto e repentinamente encerrada em 10 de setembro de 2017, motivada por protestos de grupos no espaço cultural, em Porto Alegre, e nas redes sociais da instituição e do banco. A mostra que deveria permanecer até 8 de outubro, contava com mais de 270 obras, pinturas, gravuras, fotografias, colagens, esculturas, cerâmicas e vídeos, oriundas de coleções públicas e privadas, que exploravam a diversidade de expressão de gênero. Visitantes da mostra manifestaram-se contrários à manutenção da exposição (GOBBI, 2017).

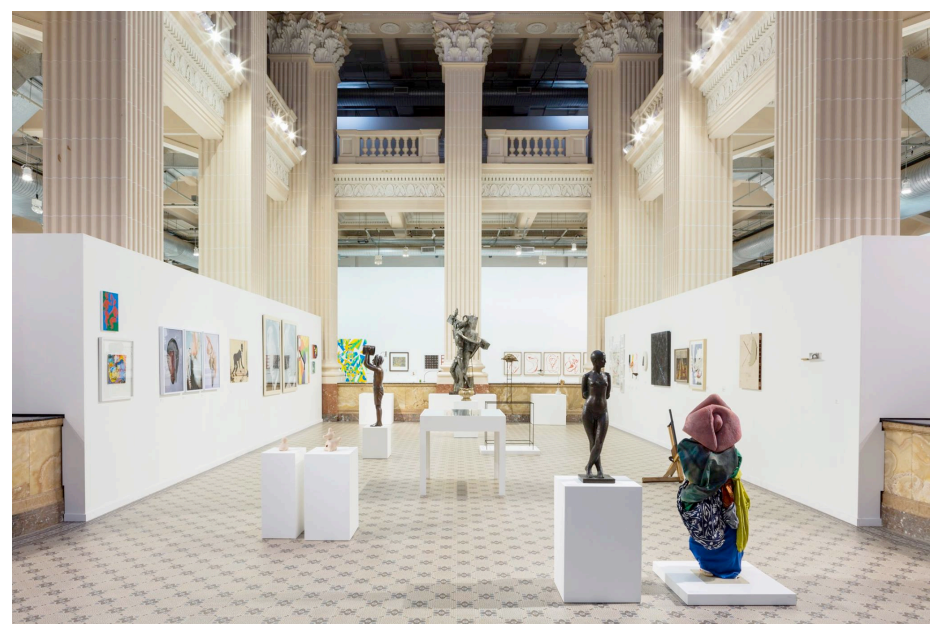

Figura 5: Queermuseu - Cartografias da Diferença na Arte Brasileira. Fonte: Fredy Vieira, 2017 (SANTANDER CULTURAL, 2017)

Segundo Gaudêncio Fidélis, curador da mostra, a exposição busca “[...] tratar de um conjunto de problemas artísticos que nos demanda navegar por um meandro de questões culturais, históricas, sociais e conceituais, cuja complexidade não é só admirável, mas também extremamente importante para a sociedade contemporânea (FIDÉLIS, 2017, p. 3).

Além de Lygia Clark, outras artistas mulheres comparecem à exposição Queermuseu: Adriana Varejão, Bia Leite, Cibele Vieira, Sandra Cinto, dentre outras. Convém acentuar que o número de expositoras é bastante reduzido, quando comparado ao 
de artistas homens. De outra forma, é importante pensar sobre as repercussões da mostra Queermuseu: necessitamos ainda de muita discussão a respeito dos temas trazidos nas visualidades contemporâneas. Embora a exposição tenha sido mal compreendida por certos grupos, ela

[...] promove o questionamento entre a realidade das obras e o mundo atual. Algumas peças apresentadas na mostra revelam imagens que podem provocar um sentimento contrário daquilo que discutem. Porém, foram criadas justamente para nos fazer refletir sobre os desafios que devemos enfrentar em relação às questões de gênero, diversidade, violência entre outros (SANTANDER CULTURAL, 2017).

Rosana Paulino aponta reflexões sobre a questão feminina em sua produção artística, promovendo questionamentos sociais, étnicos e de gênero. Nascida em São Paulo em 1967, Paulino utiliza linhas e agulhas, tecidos e objetos "banais" para elaboração de suas obras (Fig. 6). A artista afirma que "o fio que torce, puxa, modifica o formato do rosto, produzindo bocas que não gritam, dando nós na garganta. Olhos costurados, fechados para o mundo e, principalmente, para sua condição de mundo" (PAULINO, 1997 apud TVARDOVSKAS, 2010).

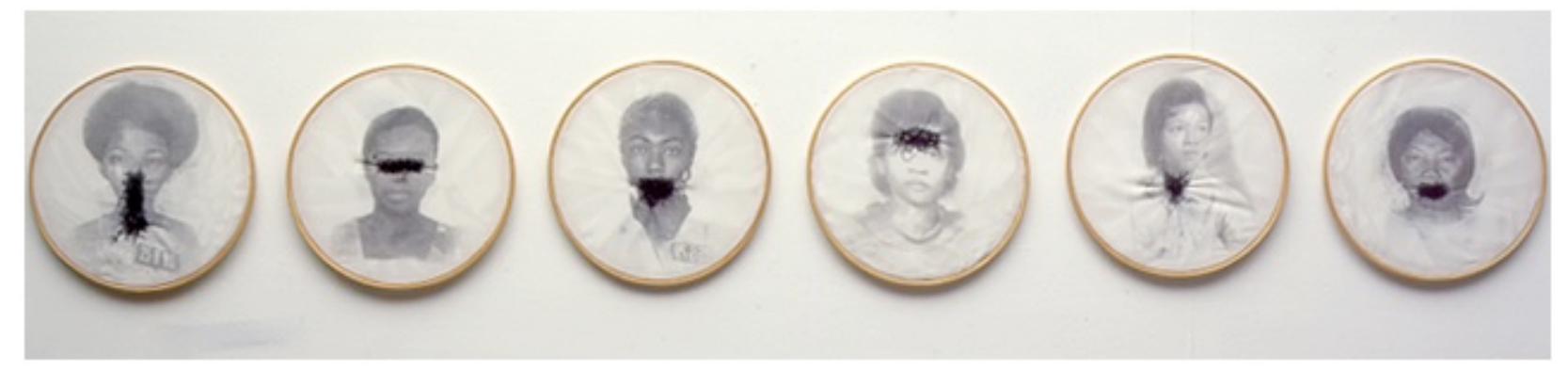

Figura 6: Série Bastidores, 1997, imagem transferida sobre tecido, bastidor e linha de costura, $30 \mathrm{~cm}$. Fonte: ESQUERDA DIÁRIO, 2017.

$\mathrm{Na}$ série Bastidores, a artista apresenta a condição da mulher negra na sociedade brasileira a partir de imagens que expressam uma supressão de seus direitos. Questões de gênero e de etnia são demonstradas na série, na qual a artista procura expressar o machismo e o racismo que ainda oprimem muitas mulheres brasileiras (PIMENTEL, 2017).

Desta forma, em seus trabalhos, é apresentada uma expansão no campo das artes visuais, apresentando obras que transitam entre a escultura e o objeto, a gravura, a fotografia e a pintura, e mesmo, revela-se em instalações-performance, buscando inserir 
nestas variadas linguagens artísticas, o cotidiano da mulher brasileira, por meio da utilização de objetos simples, de uso doméstico.

Portanto, por meio da compreensão de trabalhos das Guerrilla Girls, de Lygia Clark, Rosana Paulino e da mostra Queermuseu, é possível refletir sobre a importância do estudo sobre os dispositivos visuais e as tecnologias da representação - no caso, as artes visuais - promovendo a criticidade a respeito destas. A escola, como espaço de fabricação de sujeitos e produção de identidades pode colaborar para a discussão a respeito da representação feminina na sociedade, a partir da arte e seus desdobramentos.

\section{Conclusões}

Neste trabalho buscamos argumentar a favor de uma educação crítica das imagens, no sentido de ampliar a compreensão das visualidades que nos cercam cotidianamente. Verifica-se a necessidade dos estudos sobre a cultura visual ampla, visando ampliar os entendimentos sobre os espaços e as maneiras como a cultura se torna visível e o visível se torna cultura. Sabemos que a escola, ao mesmo tempo, que propõe a difusão de conhecimentos, também opera no sentido de produção de sujeitos e identidades - de gênero, classe ou etnia - em contextos de relações de desigualdade.

Consequentemente, a desnaturalização de formas preestabelecidas é fundamental para a educação em artes visuais, de forma que a escola possa ser um espaço propiciador de novas culturas, visto que se tempo e espaço foram aprendidos e interiorizados por diferentes grupos sociais ao longo da história, necessitamos de renovação constante e reflexão permanente. Os saberes resultantes dos processos educativos que podem ser adquiridos em todo o lugar em que o conhecimento é produzido, resultam em pedagogias culturais que extrapolam os limites da escola, nos proporcionando o entendimento de que a cultura é uma área privilegiada de produção de significações para os sujeitos.

Assim, é fundamental o questionamento sobre a presença do feminino na área da cultura e das artes visuais, pois é ainda dominada predominantemente pela visão masculina, em função do maior destaque dado à produção de artistas homens, em toda história da arte ocidental, em especial. Historicamente as mulheres têm aparecido como modelos, sendo retratadas nas obras de arte, e não como protagonistas dos fazeres artistas. Portanto, o conhecimento das artistas mulheres, em especial, pode favorecer uma nova apreensão das visualidades contemporâneas, buscando superar as desigualdades de gênero. 


\section{Referências}

ANDRADE, Paula Deporte de; COSTA, Marisa Vorraber. Usos e possibilidades do conceito de pedagogias culturais nas pesquisas em estudos culturais em educação. Textura. Canoas, v.17 n.34 p.48-63 mai./ago. 2015, p. 48-63.

BAITELLO, Jr. Norval. A era da iconofagia. Ensaios de comunicação e cultura, São Paulo: Hacker, 2005.

BUTLER, Judith. Problemas de Gênero - feminismo e subversão da identidade. 9 ed, Rio de Janeiro: Civilização Brasileira, 2015.

BORTOLON, Flavia Araújo. A nostalgia do corpo: a construção do corpo na obra de Lygia Clark. 2015. 112f. Dissertação (Mestrado em História) - Universidade Federal do Paraná. Disponível em: <http://acervodigital.ufpr.br/handle/1884/39875?show=full> Acesso em: 13 set. 2017.

ENCYCLOPEDIA BRITANNICA. Jean Auguste Dominique Ingres (Biografia). Disponível em: < https://global.britannica.com/biography/J-A-D-Ingres> Acesso em: 13 set. 2017.

ESCOSTEGUY, Ana Carolina. Estudos Culturais: uma introdução. In: SILVA, Tomaz T. (Org.). O que é, afinal, Estudos culturais? 4 ed. Belo Horizonte: Autêntica, 2010, p. 133-166.

FIDÉLIS, Gaudêncio. Diferença e diversidade: em direção a uma convivência não normativa com a arte. Ação Educativa - Material de Apoio/Caderno do Professor Queermuseu - Cartografias da diferença na arte brasileira. Porto Alegre: Santander Cultural, 2017, p. 1-16.

GIROUX, Henry; MCLAREN, Peter. Por uma pedagogia crítica da representação. In: SILVA, Tomaz T.; MOREIRA, Antônio F. (Orgs.). Territórios contestados: O currículo e os novos mapas políticos e culturais. Petrópolis: Vozes, 1998, p. 45-67.

GIROUX, Henry (1995). Praticando estudos culturais nas faculdades de educação. In: SILVA, Tomaz T. (Org.). Alienígenas na sala de aula: Uma introdução aos estudos culturais em educação. 3 ed. Petrópolis: Vozes, 1995, p. 131-159.

GOBBI, Nelson. Em nota a clientes, Santander explica encerramento de mostra LGBT em Porto Alegre. Santander Cultural encerrou exposição "Queermuseu" após receber críticas. Disponível em: $<$ https://oglobo.globo.com/cultura/artes-visuais/em-notaclientes-santander-explica-encerramento-de-mostra-lgbt-em-porto-alegre 21807901\#ixzz4saUuMN9Z> Acesso em: 11 set. 2017.

GROSENICK, Uta. Mulheres Artistas: século XX e XXI. Taschen, 2003.

GUERRILla GIRLS. Do Women Have to be Naked to Get into the Met. Museum? (1989). Disponível em: <http://www.guerrillagirls.com/>Acesso em: 13 set. 2017.

GUERRILLA GIRLS. Guerrilla Girls em Nova Iorque, 1985. Disponível em:

$<$ https://revistacult.uol.com.br/home/guerrilla-girls-no-brasil-masp/ > Acesso em: 13 set. 2017.

HALL, Stuart. A identidade cultural na pós-modernidade. 10 ed. Rio de Janeiro: DP\&A, 2005. 
HERNÁNDEZ, Fernando. Cultura Visual - Mudança Educativa e projeto de trabalho. Porto Alegre: Artmed, 2000.

HERNÁNDEZ, Fernando. Catadores da Cultura Visual - proposta para uma nova narrativa educacional. Porto Alegre: Mediação, 2007.

ITAÚ CULTURAL. Lygia Clark (biografia). Disponível em:

http://enciclopedia.itaucultural.org.br/pessoa1694/lygia-clark> Acesso em: 13 de set. 2017.

KNAUSS, Paulo. O desafio de fazer História com imagens: arte e cultura visual, v. $8, \mathrm{n}^{\circ}$ 12, Uberlândia. Artcultura - Revista do Instituto de História da UFU, 2006, p. 97-115.

LOURO, Guacira Lopes. Gênero, sexualidade e educação: uma perspectiva pós estruturalista. $16^{\text {a }}$ ed. Petrópolis: Vozes, 2014.

MARTINS, Raimundo. Educação e poder: deslocamentos perceptivos e conceituais da cultura visual. In: OLIVEIRA, M. O; HERNÁNDEZ, F. (Orgs.). A formação do professor e o Ensino das Artes Visuais. Santa Maria: editora UFSM, 2005, p. 133-145.

MEYER. Dagmar. E. (2013), Gênero e educação: teoria e política. In: LOURO, Guacira L.; FELIPE, Jane; GOELLNER, Silvana V. (Orgs). Corpo, gênero e sexualidade. Petrópolis: Vozes, 2013, p. 11-29.

NELSON, Cary; TREICHLER, Paula. A.; GROSSBERG, Lawrence. Estudos Culturais: Uma Introdução. In: SILVA, Tomaz T. (Org.). Alienígenas na Sala De Aula - Uma introdução aos estudos culturais em educação. 6 ed. Petrópolis: Vozes, 2005, p. 7-34.

NOCHLIN, Linda. Por que não houve grandes mulheres artistas? São Paulo: Edições Aurora, 2016.

PAULINO, Rosana. Série Bastidores, 1997. Disponível em:

$<$ http://www.esquerdadiario.com.br/Rosana-Paulino-a-mulher-negra-na-arte $>$ Acesso em: 13 set. 2017.

Biografia. Disponível em: $<$ http://www.rosanapaulino.com.br/biografia/> Acesso em: 13 de set. 2017.

PIMENTEL, Jonas. Rosana Paulino: a mulher negra na arte. Disponível em: $<$ http://www.esquerdadiario.com.br/Rosana-Paulino-a-mulher-negra-na-arte $>$ Acesso em: 13 set. 2017.

PERFORMING USER. O eu e o tu (1967). Disponível em: $<$ https://itp.nyu.edu/classes/performinguser/> Acesso em: 13 set. 2017.

SANTANDER CULTURAL. Queermuseu - Cartografias da Diferença na Arte

Brasileira. Disponível em:

<https://www.facebook.com/SantanderCultural/posts/732513686954201>

Acesso em: 14 set. 2017.

SCOTT, Joan. Gênero: uma categoria útil de análise histórica. Educação \& Realidade. Porto Alegre, vol. 20, nº 2, jul./dez, 1995, p. 71-99.

SILVA, Tomaz T. A produção social da identidade e da diferença. In: SILVA, Tomaz T. (org.). Identidade e diferença: A perspectiva dos estudos culturais. 11 ed. Petrópolis: Vozes, 2012, p. 73-102. 
TATE. Guerrilla Girls. Do Women Have to be Naked to Get into the Met. Museum? (1989). Disponível em: <http://www.tate.org.uk/art/artworks/guerrilla-girls-do-womenhave-to-be-naked-to-get-into-the-met-museum-p78793> Acesso em: 14 set. 2017.

TVARDOVSKAS, Luana S. Rosana Paulino: “é tão fácil ser feliz?”. Revista Gênero. Niterói, v. 10, "n. 2", 2010, p. 235-25. Disponível em:

$<$ http://www.revistagenero.uff.br/index.php/revistagenero/article/view/25> Acesso em: 14 set. 2017.

UNIVERSIA. A grande Odalisca. Disponível em:

$<$ http://noticias.universia.com.br/destaque/noticia/2012/03/30/920735/conheca-grandeodalisca-jean-auguste-dominique-ingres.html\#> Acesso em: 14 de set. 2017. 